\title{
You Can Glue It. We Can Help.
}

\author{
ERIN BESLER
}

Princeton University

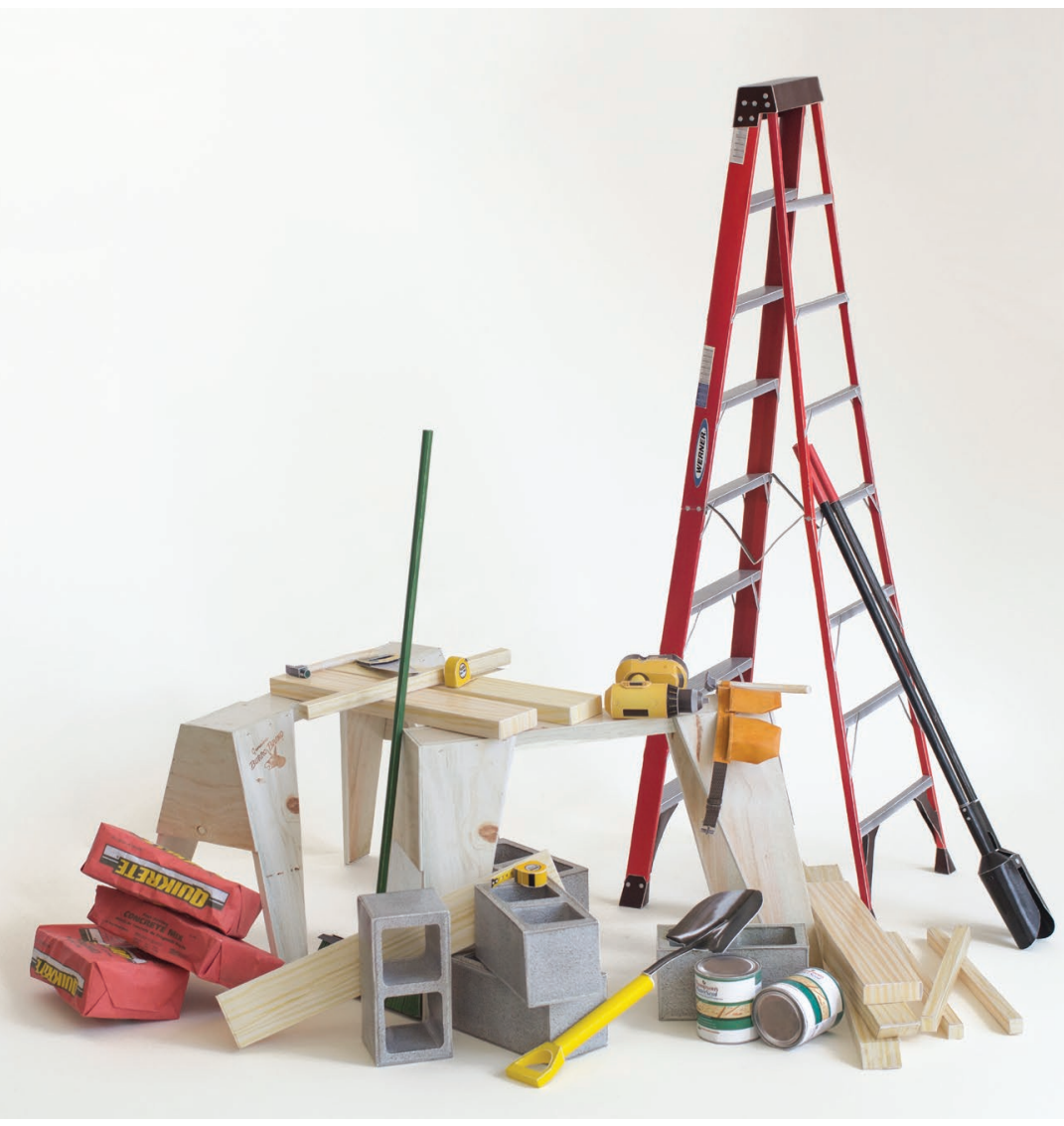

Figure 1. Besler \& Sons, Enjoy Your Deck :-), 2017 Chicago Architecture Biennial. Photo courtesy Dongxiao Cheng.

This paper presents a project recently exhibited at the 2017 Chicago Architecture Biennial, which uses the architecture exhibition as a platform to clear creative space for outcomes that rely less on architecture's expertise and mastery, and more on ubiquity and access. Those that are built on audience participation and spans of attention, and are the result of engaging various constituents in the production and exhibition of architecture, from historians to weekend warriors, construction workers to economists, YouTube stars to soccer moms, and social activists to social media influencers.

Though the role of participation in the history of art is well recognized and wide ranging, ${ }^{1}$ architecture and the exhibitions that surround it have been predominantly invested in absolutes, assurances. Of course, architecture has many participants, from clients and community members to consultants and contractors, but, with few exceptions, their status is rarely elevated to the level of a producer in ways that we might see in participatory art. The outcomes of participation in creative and productive practices tend to be less clearly defined than conventional architectural design processes are generally comfortable with. Because a project may develop across the span of weeks or months, or based solely on the number of visitors who attend an exhibition or contribute, and even though it may still insist on rules and established interactions, architecture has largely resisted participation as a component of design practices, and by extension, buildings, installations, and exhibitions. The design practice, Besler \& Sons, co-founded by myself and Ian Besler, is interested in clearing creative space for perhaps less defined outcomes, those that are built on audience participation and spans of attention. The work that emerges suggests a new approach in architectural practice, of engaging constituents 

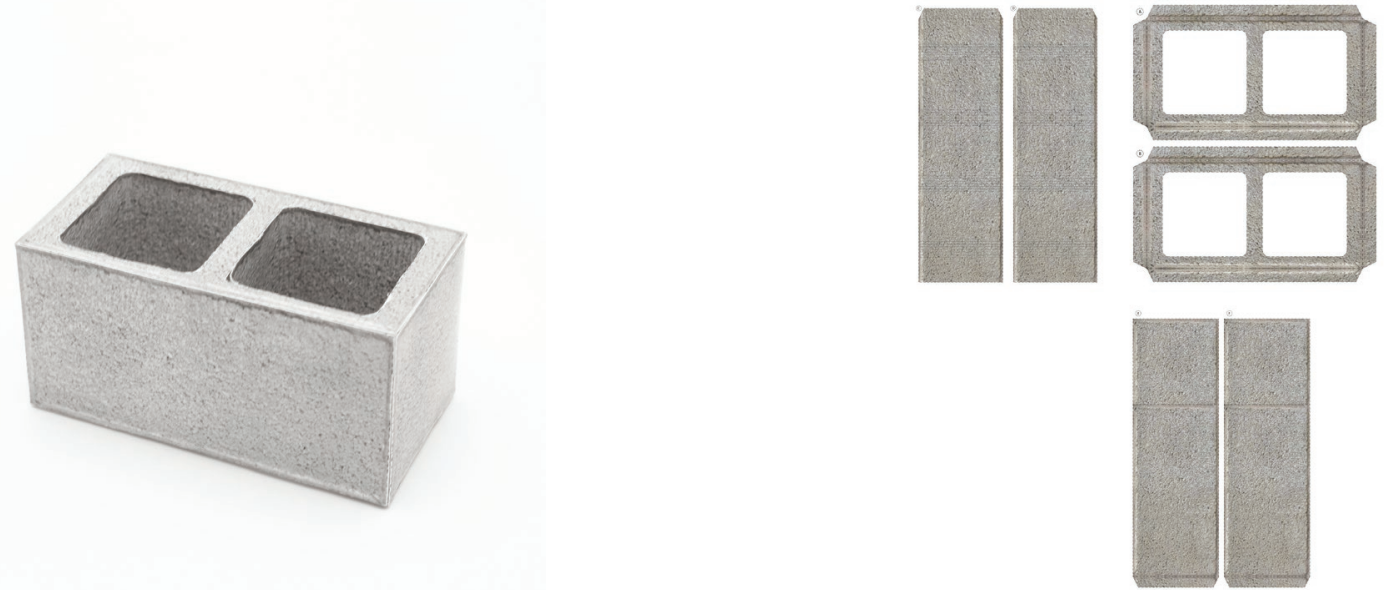

Figure 2. Besler \& Sons, Enjoy Your Deck :-), 2017 Chicago Architecture Biennial. Photo courtesy Dongxiao Cheng.

who are typically disregarded in the production and exhibition of built form: from historians to weekend warriors, construction workers to economists, YouTube stars to soccer moms, and social activists to social media influencers.

So, when we were approached by the curators of the Chicago Architecture Biennial in 2017 to produce a model for the exhibition "Horizontal City," we were eager to embed these issues into the exhibited work. We were asked to choose a canonical image of an architectural interior, from any time period, and reconstruct it as a scale model, to 'replay' it in the curator's terms. ${ }^{2}$ Of course, the history of architecture offers plenty of illustrations and photographs of canonical interiors, many with their own substantial and complex subtexts that are not necessarily evident in the image itself. But it seemed to us that the architectural imagery that we engage with dayto-day would be more productively challenging to translate into physical models because social media and online platforms have a capacity to embed and entangle many of these subtexts into the content itself, as metadata or other associated links, hashtags, and comments.

The project that developed from these observations, titled "Enjoy Your Deck :-)" is an architectural model of an online "how-to" home improvement video. The project reframes online video sharing platforms as a category of media that circulates imagery, while simultaneously generating an attendant set of language, media, data, and associations, such as through comment sections, view count statistics, recommendations for related viewing, popup advertisements for local lumber yards, closed captions, and various options for sharing with friends and across social media.

The online instructional video provides opportunities for us to rethink the limits of differentiations that are typically perceived between expert and amateur practices in architecture, building, and design, and their increasing inadequacy for many models of production. Self-made, self-composed, and often self-narrated, the video tutorials that the "D.I.Y" aspirant produces and circulates today on YouTube and other popular online video sharing platforms are short, narrative clips that provide us with a unique perspective of how construction and building practices manifest in media imagery, and how issues of labor, competency, and discourse are staged around these sites of production.

Through sheer volume (we find 272,000 results on YouTube in a search for "DIY Home Improvement") and ease of circulation, this category of media is elevated into the canon by proscribing the "official" ways of doing and offering a space in the comments section for the ongoing litigation of terms, methods, and best practices. Amateur instructional videos reveal, translate, and mediate broader historical and societal establishments of class, creativity, consumerism, leisure, computational mastery, digital savvy, and millennialage entrepreneurial self-assertion. And given that almost all amateur instructional videos are recorded in and around the context of the home, whether it be in the kitchen, the den, the bedroom, or the bathroom, they are inscribed with a uniquely domestic focus. Particular among these settings, the backyard is made to be an interior space, one with a simultaneous productive and recreative focus. Especially in the U.S., the residential backyard is a space of display, both public and private, where aspiration, leisure, and performance are engaged through chores, projects, pastimes, and parties.

While numerous and variable, we can nevertheless identify conventions in the scope and format of many online "how-to" videos. Questions of material, budget, and tools are primary. Most projects that we find are necessarily limited to an inventory derived exclusively from Home Depot (or some other large-scale retail home improvement chain), and to a scale that can be reasonably confined to no more than one or two weekends worth of work. Judging by the volume of videos that take it as a focus, the design and construction of the backyard deck exemplifies all of these criteria. 

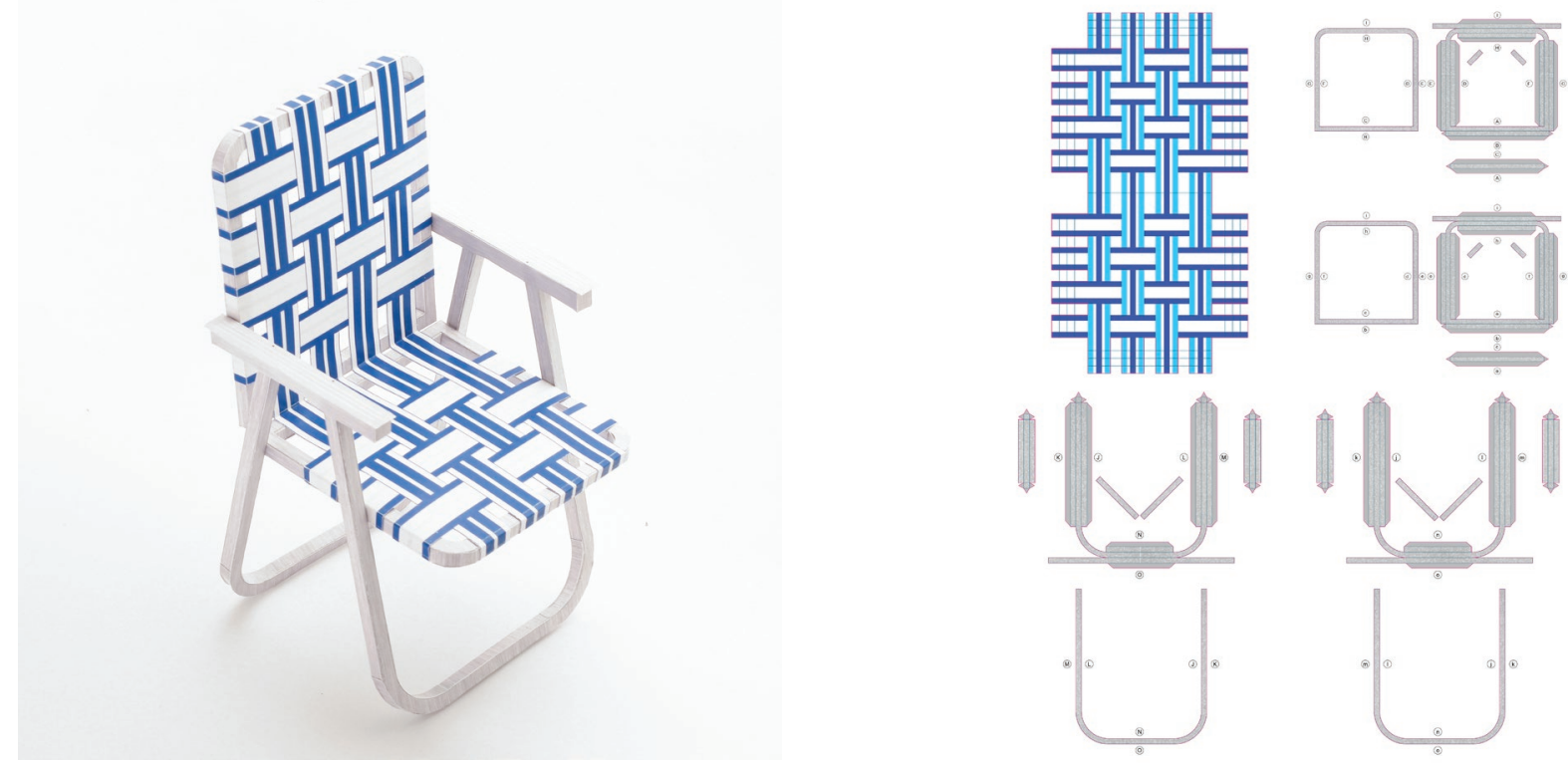

Figure 3. Besler \& Sons, “Enjoy Your Deck :-)," 2017 Chicago Architecture Biennial. Photo courtesy Dongxiao Cheng.

Requiring little more than concrete, dimensional lumber, hardware, and basic power tools, the backyard decks that manifest within the running time of these online videos are surprisingly versatile architectural forms. Their formal complexity, size, and architectural style can be made to fit the site; sometimes unambitious, they will stick to a simple plan, tethered conservatively to a sliding glass door, and in other instances, taking on multiple levels, enveloping an existing tree, or wrapping around the side of the house.

Regardless of the details of construction, as viewers, our readings of these videos are informed as much by the expository prompts that our narrators provide ("Building a deck will definitely take some time, but in the end, it's worth it!"3), as by the choices of framing, editing, on-screen captions, asides, and digressions.

The architecture exhibition can be thought of as a platform that clears creative space for outcomes that rely less on architecture's expertise and mastery, and more on ubiquity and access. In doing so exhibitions have the ability to leverage the accessibility of built form alongside the general public's habits and familiarity with experiences that surround viewing and interacting with architecture as vital forms of contemporary communication of architectural ideas and frameworks. Much of this work is focused on producing tools and platforms that give rise to their own archives, digital warehouses, and sites for generating, storing, sharing, accessing, and downloading architecture.

\section{AN EXHIBITION WORKBOOK}

In the space of the office, on a job site, or an exhibition, we tend to feel comfortable making unqualified assertions about how we use our time. This is what elevates it from idle activity to the status of a "work," with budgets, schedules, and shop drawings. Perhaps it's the certainty of paper that feels so reassuring in its ability to decisively assert the distinction between work and play. The credibility of a piece of paper lends credibility to the labors that it represents: a project brief, an invoice, a receipt, a business card.

Perhaps this phenomenon is most concisely represented by the labels that are used to distinguish certain categories of published material. For instance, an elementary school student might begrudgingly bring home a "workbook," often printed on the pulpiest of newsprint; its pages replete with empty boxes or void underlines demanding to be correctly filled-in. And a sympathetic parent might offer-up, as an incentive, an "activity" book, which typically includes word searches, connect-the-dot drawings, mazes, illustrations for coloring, stickers, cut-outs, and other more tactile and ephemeral pursuits. While these puzzles and diversions surely involve some measure of prescriptiveness in their outcomes, the emphasis is on leisurely diversion rather than completion.

Judging by the shift in terms - from the explicitness of "work," which has a clear and objective state of doneness, to the soft ambiguity of "activity," which may never be complete - we might hope to find some clarity in the distinction. However, in this example, the terms seem to relate not only to the contents of the page, but more so to defining what is expected from the audience. A "workbook" requires, and in fact, demands the reader's participation in order for it to fulfill its purpose as a tool of instruction. Whereas an "activity book" seems to be unburdened by a specific pedagogical agenda, it simply offers a series of idle distractions in exchange for the reader's time and limited attention. 
Published in 1905, The House That Glue Built stands out as a printed artifact that uniquely aspires to resituate the more workerly tasks of architecture as sources of leisure, while simultaneously shifting the leisurely associations of an activity book into sources of diligent labor and self-discipline. Conceived and written by Clara Andrews Williams and illustrated by George Alfred Williams, it unfolds as a sequence of interior residential spaces - moving page-to-page from the entry hall, to the library, dining room, kitchen, bedrooms, and nursery - in a house that is both a book and an instruction manual for how best to furnish a contemporary domestic interior. ${ }^{4}$ Accompanying each unfurnished architectural space is a page of haphazardly oriented accessories and accents, including tables, candles, chairs, books, and ornately framed paintings, ready to be carefully cut-out. A textual story on the facing pages describes the eponymous Glue family's tour through the house and the decorating process, offering narrative clues for the best orientations and layouts of the inventory of items, a sort of cheatsheet for the reader, who is expected to neatly and correctly glue each item into place.

Over a hundred years later, when copied and recycled imagery serves as the proverbial glue holding our visual culture together, perhaps we're slightly less enamored of the supposed proscriptive or societally corrective capacities of design and décor. Rather, we find that our attention tends to dwell on the implications of mass standardization and mainstream availability of building materials, tools, and methods that would have been historically inaccessible or otherwise privileged.

So, with a similarly fierce desire to get it right, we offer here a sort of addendum, or a late entry to The House That Glue Built: a concrete masonry unit and a lawn chair, unfolded and flattened for the diligent reader's reassembly, originally produced for the 2017 Chicago Architecture Biennial, made available here for your own desktop display. If you opt to cut-out and glue together the various pieces, you'll find that these paper models have no particular scale - they're scaled to fit within these page dimensions. Although construction materials, like CMU, lumber, and bags of concrete, have quite specific material and object qualities, there's a strange legibility to the constructed paper model, particularly when it comes to scale. If you're so inclined, you can duplicate and assemble as many paper CMUs and lawn chairs as you like.

Or not. It's your time, you can spend it however you like. But why not do something productive?

Portions of this text were previously published in an essay co-authored with Ian Besler in Pidgin Magazine \#24. Paper models designed with Dongxiao Cheng and Chase Galis.

\section{ENDNOTES}

1 See, for example, Claire Bishop, Aritificial Hells: Participatory Art and the Politics of Spectatorship (London; New York: Verso, 2012).

2 Sharon Johnston, Mark Lee, Sarah Hearne, and Letizia Garzoli, "Horizontal CityRoom of Plinths, Guidelines," PDF emailed to participants, December 23, 2016.

3 Lowe's Home Improvement, "How to Build a Deck, Part 6: Installing Deck Railings, Balusters, Lattice and Skirting," YouTube, 4:11, January 3, 2013. https:// www.youtube.com/watch?v=zEkiloK_M7I.

4 Christie D. Jackson, "With Paper and Glue: Building the Commercial Success of an Arts and Crafts Toy," Winterthur Portfolio 44 (2010): 351-386. 